\title{
The gambling control bill: time for action
}

\author{
Colin $\mathrm{O}^{\prime}$ Gara $^{1,2, *}$ \\ ${ }^{1}$ Saint John of God Hospital, Stillorgan, Co. Dublin, Ireland \\ ${ }^{2}$ School of Medicine and Medical Sciences, University College Dublin, Belfield, Dublin, Ireland
}

\begin{abstract}
A modern regulatory framework for gambling in Ireland is urgently required. The Gambling Control Bill of 2013 represents a decent starting point in developing player protection and much needed treatment services and research facilities for Gambling Disorder. The drafting and enactment of the Gambling Control Bill of 2013 appears to have slipped from legislative priority. The sooner this bill is enacted the better.
\end{abstract}

Received 17 July 2017; Revised 27 September 2017; Accepted 27 October 2017; First published online 4 December 2017

Key words: Addiction, control, gambling, Ireland, legislation.

\section{Gambling disorder}

Gambling addiction was reclassified as 'Gambling Disorder' in DSM 5 (American Psychiatric Association, 2013) within the new 'Substance-Related and Addictive Disorders' section. Prior to this it was situated in the 'Impulse Control Disorders' section which includes the disorders trichotillomania and pyromania. This was to due to a significant amount of evidence presented to the DSM 5 working group on the overlap of Gambling Disorder with alcohol and substance addictions. Key clinical features of Gambling Disorder substantially overlap with those of alcohol and substance addictions. Tolerance, irritability on cutting down, repeated unsuccessful efforts to control, preoccupation, distress, lies, loss of relationships, loss of occupation, loss of opportunities and relying on others to relieve financial distress are all clinical features that are equally prominent in Gambling Disorder as they are in alcohol and substance addiction. In addition, Gambling Disorder and substance addictions share similar psychiatric comorbidities (Petry et al. 2005). Elevated rates of psychiatric and addictive comorbidity are found in Gambling disorder (Petry et al. 2005; Kessler et al. 2008). Meta-analysis (Lorains et al. 2011) indicates the highest rate of comorbidity with Gambling Disorder is nicotine dependence $(60 \%)$ followed by substance use disorder $(58 \%)$, any type of mood disorder (38\%) and any type of anxiety disorder (37\%). Furthermore, Gambling Disorder, like alcohol and drug addiction attracts considerable public stigma (Hing et al. 2016). The reclassification of Gambling Disorder in the addictions

* Address for correspondence: C. O'Gara, MRCPsych PhD, UCD School of Medicine, Saint John of God Hospital, Stillorgan, Co. Dublin, Ireland.

(Email: colin.ogara@sjog.ie) section of DSM 5 also occurred as a result of accumulated scientific evidence revealing the underlying brain substrates in Gambling Disorder (Bowden-Jones \& Clark, 2011). First, functional magnetic resonance imaging demonstrated impairment of ventromedial prefrontal cortex functioning, an area of the brain thought to be critical in risk processing (Potenza, 2008). Second, various neuropsychological data support faulty risk evaluation and persistence with gambling in the face of adverse consequences (Bowden-Jones et al. 2005; Goudriaan et al. 2006; Lawrence et al. 2009). The reclassification of gambling addiction in DSM 5 as an addictive disorder further strengthens calls on the current Government to modernise gambling legislation, alongside alcohol and drug legislation.

\section{Gambling control bill 2013}

Gambling in Ireland is still operated under the outdated 1931 Betting Act (Office of the Attorney General, 1931) and the 1956 Gaming and Lotteries Act (Office of the Attorney General, 1956). Under this legislation, casino gambling in Ireland is illegal however Irish casinos have sidestepped this legislation by operating as private members clubs, which are excluded from the 1956 legislation. Minister Alan Shatter, Minister for Justice, Equality and Defence approved the general scheme of the Gambling Control Bill in 2013. Continued drafting of the Bill was expected towards final enactment however a time frame was not specified. Since then, the Bill appears to have slipped from legislative priority. As the years have passed since 2013, successive governments have generally indicated that drafting of the Bill was imminent. Unfortunately there has been no movement on drafting and enactment of the Bill. One of the consequences of this inaction is that is 
that there is no national treatment framework for those suffering from Gambling Disorder.

\section{Treatment and management of gambling disorder}

Specialist units are required in Ireland to provide community based and residential treatment for Gambling Disorder. Referrals to these services will likely vary in severity from mild whereby 4-5 of DSM 5 diagnostic criteria for Gambling Disorder are met to severe where 8-9 are met. Severe Gambling Disorder is associated with increased suicidal ideation, suicide attempts and completed suicides (Russo et al. 1984; Black et al. 2015), hence the need at times for intensive monitoring in the inpatient setting. Clinical teams should be Consultant Psychiatrist led, multidisciplinary in nature, comprising of input from psychiatry, psychology, addiction counselling, family therapy, debt management, bereavement counselling and a range of complimentary therapies. In addition a key focus of these units should be on closing the research gap on gambling data in Ireland. Enactment of the Gambling Control Bill will provide for the establishment of a 'Social Gambling Fund' whereby land based and remote gambling operators based in Ireland and other jurisdictions will contribute a levy. This levy will be based on turnover of the operator and will be mandatory. As the turnover of gambling operators in general tends to be high, this should ensure the fund for service provision and research is substantial. This should hopefully enable the development of treatment services for Gambling Disorder throughout the country as well as much needed research facilities.

\section{Conclusion}

Although we currently do not have data on the prevalence of Gambling Disorder in Ireland, our clinical observations on presentations for treatment suggest it is an increasing problem. This appears to be as a result of the increased availability of gambling both within bookmakers and online. There are no current controls on the vast amount of gambling adverts in the popular media and online. Recent changes in the classification of gambling addiction to the 'Substance Related and Addictive Disorders' in DSM 5 is due to the overlap of Gambling Disorder with alcohol and drug addiction both clinically and scientifically. This change has added further weight to the call for implementing a modern regulatory framework for gambling in Ireland. The Gambling Control Bill of 2013 was due for drafting and enactment following the publication of its general scheme in 2013. It appears to have slipped from legislative priority since then however. The Gambling Control Bill represents a decent starting point in developing player protection and much needed treatment services and research facilities for Gambling Disorder. The sooner this bill is enacted the better.

\section{Acknowledgements}

The author, Dr. O'Gara asserts that all procedures contributing to this work comply with the ethical standards of the relevant national and institutional committee on human experimentation with the Helsinki Declaration of 1975, as revised in 2008.

\section{Financial Support}

This research received no specific grant from any funding agency, commercial or not-for-profit sectors.

\section{Conflicts of Interest}

The author has no conflicts of interest to disclose.

\section{References}

American Psychiatric Association (2013). Diagnostic and Statistical Manual of Mental Disorders, 5th edn. DSM-5. APA. Washington, DC.

Black DW, Coryell W, Crowe R, McCormick B, Shaw M, Allen J (2015). Suicide ideations, suicide attempts, and completed suicide in persons with pathological gambling and their first-degree relatives. Suicide and Life-Threatening Behavior 45, 700-709.

Bowden-Jones H, Clark L (2011). Pathological gambling: a neurobiological and clinical update. British Journal of Psychiatry 199, 87-89.

Bowden-Jones H, McPhillips M, Rogers R, Hutton S, Joyce E (2005). Risk-taking on tests sensitive to ventromedial prefrontal cortex dysfunction predicts early relapse in alcohol dependency: a pilot study. Journal of Neuropsychiatry \& Clinical Neuroscience 17, 417-420.

Goudriaan AE, Oosterlaan J, de Beurs E, van den Brink W (2006). Neurocognitive functions in pathological gambling: a comparison with alcohol dependence, Tourette syndrome and normal controls. Addiction 101, 534-547.

Hing N, Russell AM, Gainsbury SM, Nuske E (2016). The public stigma of problem gambling: its nature and relative intensity compared to other health conditions. Journal of Gambling Studies 32, 847-864.

Kessler RC, Hwang I, LaBrie R, Petukhova M, Sampson NA, Winters KC, Shaffer HJ (2008). DSM-IV pathological gambling in the National Comorbidity Survey Replication. Psychological Medicine 38, 1351-1360.

Lawrence AJ, Luty J, Bogdan NA, Sahakian BJ, Clark L (2009). Problem gamblers share deficits in impulsive decision-making with alcohol-dependent individuals. Addiction 104, 1006-1015.

Lorains FK, Cowlishaw S, Thomas SA (2011). Prevalence of comorbid disorders in problem and pathological gambling: systematic review and meta-analysis of population surveys. Addiction 106, 490-498.

Office of the Attorney General (1931). Betting Act. Oireachtas of Saorstat Eireann, Dublin (http:/ / www.irishstatutebook. ie/eli/1931/act/27/enacted/en/print.html). Accessed 16th November 2017. 
Office of the Attorney General (1956). Gaming and Lotteries Act Oireachtas for Saorstat Eireann, Dublin(https:/ /www. google.ie/?gws_rd=ssl\#q=gaming+and+lotteries+act+1956 $\& \mathrm{spf}=1499693340479$ ).

Petry NM, Stinson FS, Grant BF (2005). Comorbidity of DSM-IV pathological gambling and other psychiatric disorders: results from the National Epidemiologic Survey on Alcohol and Related Conditions. Journal of Clinical Psychiatry 66, 564-574.
Potenza MN (2008). Review. The neurobiology of pathological gambling and drug addiction: an overview and new findings. Philosophical Transactions of the Royal Society of London. Series B, Biological Science 363, 3181-3189.

Russo AM, Taber JI, McCormick RA, Ramirez LF (1984). An outcome study of an inpatient treatment program for pathological gamblers. Hospital \& Community Psychiatry $35,823-827$. 